\section{GEOPHYSICAL VOLUMES OF THE HANDBUCH DER PHYSIK}

Handbuch der Physik

Herausgegeben von S. Flügge. Band 47 : Geophysik I. Pp. viii +659. 118 D.M. Band 48 : Geophysik II. Pp. viii + 1045. 198 D.M. (Berlin : Springer Verlag, 1956 und 1957.)

THE new "Handbuch der Physik" will contain three volumes on geophysics, of which these two are the only ones so far published. Vol. 47 deals with the solid Earth, and Vol. 48 mainly with the atmosphere and oceans. Both volumes consist of a series of separate essays which between them cover most aspects of the physics of the Earth. Vol. 47 contains sixteen articles, and Vol. 48 seventeen; nearly all are in English and a few in French or German.

Vol. 47 opens with an article by Spencer Jones on the rotation of the Earth. This is largely concerned with the fluctuations in the rate of rotation, the nature of which has become much clearer in recent years owing to the improved time-keeping possible with quartz oscillators and atomic clocks.

Seismology is treated in a group of six papers by J. Coulomb, K. E. Bullen, W. M. Ewing, F. Press and $H$. Baule. Much of the material is familiar, but the article by Ewing and Press on surface and guided waves gives much new data on a branch of the subject that is advancing rapidly and has been unjustly neglected in the past.

Gravity and isostasy are discussed by G. D. Garland, the structure of the crust by W. M. Ewing, the forces in the crust by A. E. Scheidegger, and the figure of the Earth by K. Jung. Scheidegger's discussion demonstrates how far from solution the major problems of geology still are. In spite of our greatly increased knowledge of what has to be explained, we are still entirely uncertain of the nature of the forces that mould the crust into mountains, island ares and plateaux.

The longest article in this volume is that by $\mathrm{J}$. T. Wilson, R. D. Russell and R. M. Farquhar on radioactivity and the age of minerals. This is a valuable review of a subject that has not been treated elsewhere in such detail. The use of radioactive methods of age determination should give a new precision and definiteness to the correlation of pre-Cambrian rocks, and a review by three authors who have done so much to make geological sense of the results is most welcome.

The remaining articles are by $J$. A. Jacobs on the interior of the Earth, by L. Caignard on electric currents in the Earth, and by S. K. Runcorn on the magnetization of rocks and the magnetism of the Earth's body.

Vol. 48 opens with a 154-page article by A. Eliassen and E. Kleinschmidt on dynamic meteorology. Most of this is devoted to general theory and to the properties and formation of vortices. The general circulation and the jet streams are dealt with only briefly.

There are four articles on radiation in the atmosphere, by F. Möller, W. K. Middleton, Z. Sekera and J. Bricard. The space given to this subject seems excessive in relation to tho rather brief treatment of some important parts of the dynamical article. The related question of ozone in the atmosphere is treated by $H$. Paetzold and E. Regener. Other meteorological by $\mathrm{H}$. Paetzold and E. Regener. Other meteorolog on sound propagation in air by $\mathrm{E}$. Cox, atmospheric electricity by R. Mühleisen, and the physics of clouds by F. H. Ludlam and B. J. Mason. The latter contains a striking photograph of the production of a towering cumulus cloud by seeding.

An article on meteors by A. C. B. Lovell gives a great deal of information that will be new to most readers, including a discussion of data on upper atmospheric winds derived from the motion of meteor trails.

The section on the oceans opens with a general review by H. V. Sverdrup and an article on waves by H. U. Roll. These are followed by four articles on tides. J. Bartels discusses and tabulates the tide-generating forces, and A. Defant, W. Kertz and R. Tomaschek discuss the tides of the oceans, the atmosphere and the solid Earth. Tomaschek's article contains information that is not otherwise easily accessible.

The book ends with an article by S. Sakuma and T. Nagata on physical volcanology. This is concerned mainly with the distortions of the Farth and magnotic changes associated with volcanic eruptions.

Clearly a very great effort has gone into the production of these volumes, and care has been taken to obtain a complete coverage of the subject. The result is a valuable reference work and a convenient means of learning about many matters in which there is widespread interest. Unfortunately the price is so high that few will be able to own the books, and Vol. 47 is so heavy ( $4 \frac{1}{2} \mathrm{lb}$.) as to be unreadable except at a table.

E. C. Bullard

\section{PROBLEMS OF HIGH-SPEED FLIGHT}

\section{Aerodynamic Components of Aircraft at High} Speeds

Edited by A. F. Donovan and H. R. Lawrence. (High Speed Aerodynamics and Jet Propulsion, Vol. 7.) Pp. xiv +845. (Princeton, N.J.: Princeton University Press; London: Oxford University Press, 1957.) 120s. net.

THIS book is Vol. 7 of an important series of twelve volumes which is planned to give a comprehensive account of the problems of high-speed flight. Some of the volumes have already been issued, and of these Vol. 6, on the "General Theory of High Speed Aerodynamics", is of particular interest as the present volume is closely related to it. Whereas Vol. 6 treats the subject of high-speed aerodynamics in a fundamental and general way, the volume under review deals with specific problems such as the determ. ination of the aerodynamic characteristics of particular parts of the aircraft and the interaction of one part on another.

The book is arranged in seven sections, and in the first, Section $A, \mathrm{R}$. T. Jones and Doris Cohen of the Ames Aeronautical Laboratory discuss the basic assumptions of wing theory and their validity. The results obtained by the application of various theories to the calculation of air load distributions at subsonic and supersonic speeds are compared and differences analysed. 'T'he material is conveniently presented in three chapters; the first deals with fundamental considerations such as the use of sweepback in the development of wings for high-speed flight, and the second and third consider the prediction of lift and drag characteristics of the wings of various planforms at subsonic and supersonic speeds, respectively. The whole section runs to about 240 pages and gives a comprehensive account of the subject. It would 